\title{
Research on the Framework of Intelligent Command Decision System for Flood Control
}

\author{
Yao Zhang \\ Qinzhou Municipal Water Resources Bureau, China
}

\begin{abstract}
Starting from the process of flood control and flood control decision-making, the shortcomings of the traditional flood control and flood control command and decision-making system are analyzed, and an intelligent decision-making system for flood control and flood control is proposed. The structure and functions of the system framework are elaborated in detail, and the key issues in the process of building intelligent systems are pointed out. Based on the real-time information monitoring system, this intelligent system can predict the next phase of hydrometeorology, flood and other related information, help decision makers to identify risks, and optimize the best flood control dispatching plan for decision makers to choose.
\end{abstract}

Keywords: flood control; intelligent system; decision-making; system framework

\section{Introduction}

Floods are one of the most serious natural disasters in the world. Due to its unique natural and geographical conditions, China is a country with frequent floods. The annual losses caused are difficult to estimate. Therefore, flood prevention is of great concern to the people's livelihood ${ }^{[1]}$.After the first phase of the National Flood Control and Drought Relief Command System was put into operation, significant social and economic benefits were achieved. The current collection of rain and water conditions has realized automation and informatization, greatly improving the ability to grasp the rain, water, work, and disaster conditions in real time, but the judgment of flood and danger conditions is also based on manual analysis of existing information. This method of decision-making not only relies on personal experience but also has a certain lag, especially for flood disasters caused by local heavy rain, the lag of manual decision-making will seriously restrict the timeliness of flood relief.

Establishing a practical, efficient and scientific flood control decision support system to provide a platform for management and consultation for flood control work is the focus of flood control information construction [2]. Flood control dispatching decision support system's transition from automation and informatization to intelligence is the current development trend. The application of global positioning system, remote sensing technology, geographic information system, intelligent satellite image monitoring system, and computer-aided technology in flood control has greatly promoted the process of intelligence ${ }^{[3-5]}$. The application of domestic artificial intelligence in flood prevention originated in the late 1980s, especially the key scientific and technological research projects of the "Eighth Five-Year Plan" arranged by the country during the "Eighth Five-Year Plan" period, and a number of relatively successful results appeared ${ }^{[6]}$.Ma Junjian ${ }^{[7]}$ proposed a solution for intelligent flood control decision support system for hydropower plants based on B / S model; Jiang 
$\mathrm{Hao}^{[8]}$ et al. designed and developed a smart flood control decision support system for hydropower plants based on SOA system framework and WebGIS, and it has been successfully applied to the Songjiang River Intelligent Hydropower Plant in Jilin Province; Liu Sheng ${ }^{[9]}$ proposed an intelligent decision-making system for reservoir flood prevention and flood based on spatial information processing technology. At present, intelligent decision-making systems have been successfully applied in the planning, design, and management of water resources systems. However, intelligent flood control decision-making support systems with large rivers have not yet been put into use ${ }^{[6]}$.

\section{Deficiencies of Traditional Flood Control Decision-making System}

The traditional flood control flood control decision-making process mainly includes disaster risk assessment, flood control dispatching, and emergency rescue decision-making ${ }^{[3]}$.

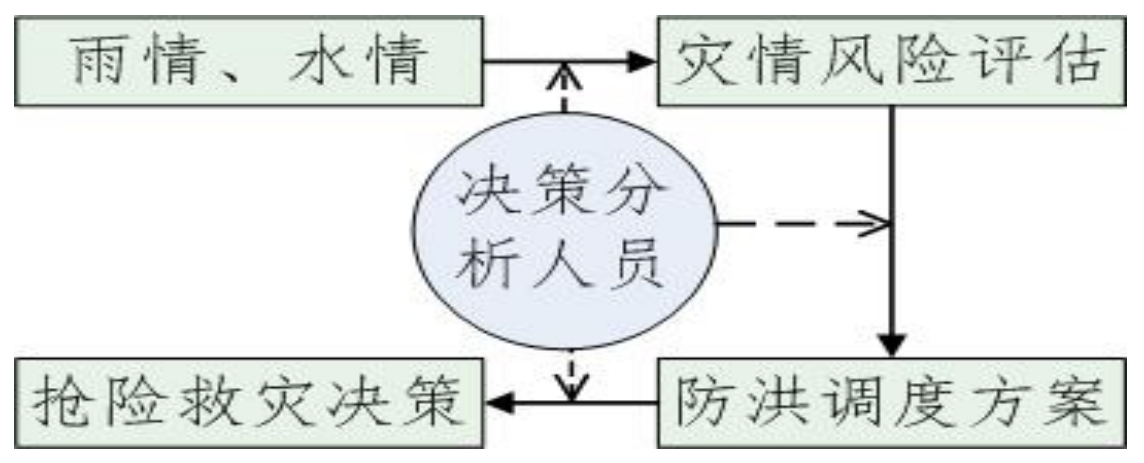

Figure 1. Traditional flood control flood control decision-making process

雨情 水情 Rain Situation, Water Situation

灾情风险评估 Disaster Risk Assessment

决策分析人员 Decision Analyst

抢险救灾决策 Emergency Rescue Decision-making

防洪调度方案 Flood Control Dispatching Scheme

(1) Disaster risk assessment: Based on real-time and forecasted water and rain information, perform scenario simulations on areas where floods may occur, estimate flood inundation areas, and analyze the severity of floods. The realtime rain and water information is provided by the hydrological station monitoring system and the reservoir real-time monitoring system; the rain and water forecast is completed by means of numerical simulation of hydrological calculations; the decision-making commander uses the geographic information system and computer-aided system to evaluate the flood affected area and inundation area.

(2) Flood control dispatching: Based on real-time and forecasted water and rain information, and working condition information, combined use of reservoirs and flood detention areas, design and optimize of flood control scheduling schemes through manual methods.

(3) Emergency rescue decision-making: According to the disaster risk assessment, formulate corresponding rescue and disaster relief plans and personnel transfer plans for possible disasters.

The traditional flood control command decision-making process relies heavily on the experience of decision-making commanders. Disaster risk assessment, flood control dispatch, and emergency rescue decision-making require a certain amount of time, and it is impossible to win more time for flood relief. The flood control intelligent decision-making system is a kind of decision-making system for non-engineering measures for flood prevention and mitigation in reservoirs designed to reduce the need for flood disasters. Based on satellite image monitoring system, geographic information 
system and a certain amount of hydrological and meteorological information monitoring, collection and processing, plus certain computer software and hardware environment support, it can provide decision makers with current and certain foreseeable periods relevant information such as hydrometeorology, floods, etc., help decision makers to identify risks, optimize the best flood control dispatching plan for decision makers to choose, and immediately notify rescue departments of decision-making through the network to improve rescue and disaster relief efficiency.

\section{System Framework Design}

Traditional flood control flood decision-making systems only use information support systems such as flood forecasting, flood control dispatching, and flood display as auxiliary tools, and rely on experts in flood control, dispatchers, and decision analysts to make flood control decisions. The flood control intelligent decision-making system is based on the geographic information system and uses real-time monitoring of river hydrology, torrents, and meteorological information to forecast floods (mountains), landslides, and debris flows that may occur in the area within the next period. According to the predicted time of the disaster, its possible impact, the affected object, etc., provide decision makers with emergency response plans.

According to the flood control decision-making process, the system structure framework can be divided into three levels: information monitoring system, information analysis system, and flood control decision-making system. Its overall structure is shown in Figure 2.

(1) The information monitoring system mainly performs real-time monitoring of meteorological and hydrological information and provides input data for hydrological forecasting, including meteorological information monitoring, flash flood early-warning monitoring, river water level monitoring, and reservoir monitoring.

(2) The information analysis system analyzes real-time meteorological and hydrological data, predicts changes in river water levels in the next period, and assesses disaster risks such as floods and mudslides; through geographic information systems, it integrates hydraulic engineering information with the spatial location of the project. The forecast flood level and other flood prevention elements are combined to accurately determine the scope of the disaster situation; through the information query and statistical system, the disaster victims are accurately identified.

(3) The flood control decision-making system is mainly based on the forecasted river hydrology and disaster risks, combined with flood control planning, emergency plans and expert knowledge bases, etc., to optimize the flood control dispatching plan and rescue decisions for decision-makers' reference.

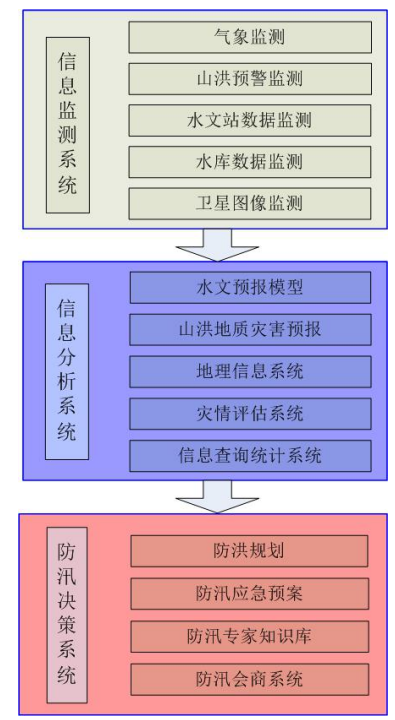

Figure 2. Intelligent system framework for flood control decision-making 


\author{
气象监测系统 Weather Monitoring System \\ 气象监测 Meteorological Monitoring \\ 山洪预警监测 Flash Flood Monitoring \\ 水文站数据监测 Hydrological Station Data Monitoring \\ 水库数据监测 Reservoir Data Monitoring \\ 卫星图像监测 Satellite Image Monitoring \\ 信息分析系统 Information Analysis System \\ 水文预报模型 Hydrological Forecasting Model \\ 山洪地质灾害预报 Flash Flood Geological Disaster Forecast \\ 地理信息系统 Geographic Information System \\ 灾情评估系统Disaster Assessment System \\ 信息查询统计系统 Information Query Statistics System \\ 防汛决策系统 Flood Control Decision System \\ 防洪规划 Flood Control Planning \\ 防汛应急预案 Flood Prevention Emergency Plan \\ 防汛专家知识库 Flood Control Expert Knowledge Base \\ 防汛会商系统 Flood Prevention Consultation System
}

\title{
4. Key Issues
}

4.1 Construction of information query statistics system.

The main data contained in the information query and statistics system are water conservancy projects, traffic roads, geographic information of key protected areas, industrial statistical information of different regions, distribution of residential areas, and emergency resettlement sites. The information stored in the system should take geographic information as one of the basic attributes. When a disaster occurs, the intelligent flood control system can automatically retrieve the affected object according to the affected area of the disaster.

\subsection{Disaster assessment.}

The key to disaster assessment is how to superimpose the typhoon-affected area or rainfall area predicted by meteorological and hydrological models with basic spatial data (geographic information) and socio-economic data (information query statistical system), and conduct disaster risk assessment.

\subsection{Application of knowledge base.}

The traditional flood control system makes flood control command decisions through consultation and judgment. The intelligent flood prevention system builds an expert flood prevention knowledge base, and when the system predicts the occurrence of a disaster, it automatically retrieves the corresponding expert decision for reference. The system has continuously evolved by continuously accumulating experience, adding new knowledge, and deleting unreasonable old knowledge to achieve continuous evolution

The knowledge base is the "brain" of the intelligent flood control system, and it is also the biggest difficulty in the process of intelligent construction. The main difficulties are: there is a difference between the way experts express their knowledge and computer expressions, so a unified problem presentation method needs to be constructed; expert knowledge has subjective diversity and uncertainty. The knowledge base system cannot guarantee whether the countermeasures 
provided are correct and optimal, and the intelligent flood control system needs further judgment ${ }^{[10]}$.

\section{System Functions}

The intelligent system for flood control decision-making has following functions: Collect and store annual meteorological and hydrological data, can quickly and accurately query geographic and meteorological information, and perform comparative analysis of relevant data and information over the years ${ }^{[9]}$; data, accurately predict rain and water conditions, and forecast possible flood conditions; can objectively and accurately evaluate disaster conditions, quickly sort out specific disaster conditions, such as time, place, disaster area personnel and material distribution, and further predict the development trend of the disaster situation; analyze the development situation of flood conditions, provide suggestions and plans based on expert knowledge and experience; comparative analysis of relevant information over years, help decision makers to formulate, evaluate and choose the best flood prevention decision-making plan; accumulate expertise on flood prevention and treatment and flood prevention decisions, enrich the system knowledge base, and improve the level of intelligence.

\section{Conclusion}

The flood control decision-making system is a kind of decision-making system for non-engineering measures for flood prevention and mitigation designed to reduce the loss of flood disasters. Although the current flood control and drought relief command system can provide timely, comprehensive, and accurate rainfall and water regime dynamics, the flood rescue decision-making mainly relies on decision analysts and has not yet achieved intelligence, which has greatly reduced the level of flood prevention and flood prevention decisions. With the in-depth construction of flood prevention information, it is an inevitable trend for the flood prevention decision system to develop intelligently.

\section{References}

[1] Jiang Rengui, Xie Jiancang, (2012) Li Jianxun. Research and Application of Three-dimensional Early Warning and Monitoring Platform for Flood Prevention. Journal of Hydraulic Engineering, 43 (6): 749-755.

[2] Huang Kang, Yu Kaisen, Yu Zhiqiang, et al. (2011) Design and Implementation of Service-oriented Flood Prevention GIS Support Platform. Journal of Zhejiang University (Science Edition), 38 (4): 456-460.

[3] Liu Xiaohui, Luo Xiangang, Liu Jiakui. (2014) Application of 3S Technology in Flood Control and Drought resistance Command Decision-making. Science of Surveying and Mapping, (3): 62-65, 93.

[4] Li Gang, Sun Peng. (2013) Application of Intelligent Satellite Image Monitoring System in Flood Prevention Early Warning. Haihe Water Resources, (2): 62-63.

[5] Wang Longbao, Tao Feifei, Lyu Xin, et al. (2016) Design and Implementation of Flood Control and Drought Prevention Command System in Huai'an District. Hydrological, (3): 66-72.

[6] Yu Dazheng, Suo Lisheng. (1999) Analysis and Design of Intelligent Decision Support System for Flood Control Dispatching. Hydrology, 7 (2): 18-23.

[7] Ma Junjian. (2013) Research on Flood Control Decision Support System of Intelligent Hydropower Plant Based on B / S Mode. Hydropower Energy Science, 31 (5): 170-172.

[8] Jiang Hao, Rui Jun, Li Kunpeng, et al. (2014) Design and Implementation of Flood Control Decision Support System for Smart Hydropower Plant. Hydropower Automation and Dam Monitoring, 38 (2): 1-4.

[9] Liu Sheng. (2015) Design of Intelligent Decision-making System for Reservoir Flood Degree. Jiangxi Water Resources Science and Technology, (5): 374-376,379.

[10] Huang Ming, Yu Dazheng, Wang Minghai. (2000) Research Status and Problems of Intelligent Decision Support System for Flood Control Dispatching. People's Yellow River, 22 (1): 5-7. 